\title{
Serbia within the European context: An analysis of premature mortality
}

\author{
Milena Santric Milicevic*†1, Vesna Bjegovic ${ }^{\dagger 1}$, Zorica Terzic ${ }^{\dagger 1}$, \\ Dejana Vukovic ${ }^{\dagger 1}$, Nikola Kocev ${ }^{\dagger 2}$, Jelena Marinkovic ${ }^{\dagger 2}$ and Vladimir Vasic ${ }^{\dagger 3}$
}

\begin{abstract}
Address: ${ }^{1}$ Institute of Social Medicine, School of Medicine University of Belgrade, Dr Subotica 15, 11000 Belgrade, Serbia, ${ }^{2}$ Institute of Medical Statistics and Informatics, School of Medicine University of Belgrade, Dr Subotica 15, 11000 Belgrade, Serbia and ${ }^{3}$ Department of Statistics and Mathematics, Faculty of Economics, University of Belgrade, Kamenicka 6, 11000 Belgrade, Serbia

Email: Milena Santric Milicevic* - msantric@med.bg.ac.yu; Vesna Bjegovic - bjegov@eunet.rs; Zorica Terzic - vlazo970@yahoo.com; Dejana Vukovic -dvukovic@med.bg.ac.yu; Nikola Kocev - nkocev@eunet.rs; Jelena Marinkovic - marinkovic.j@gmail.com;

Vladimir Vasic - drvasic@yubc.net

* Corresponding author †Equal contributors
\end{abstract}

Published: 5 August 2009

Population Health Metrics 2009, 7:12 doi:10.1 186/1478-7954-7-12
Received: 28 March 2009

Accepted: 5 August 2009

This article is available from: http://www.pophealthmetrics.com/content/7/1/12

(C) 2009 Santric Milicevic et al; licensee BioMed Central Ltd.

This is an Open Access article distributed under the terms of the Creative Commons Attribution License (http://creativecommons.org/licenses/by/2.0), which permits unrestricted use, distribution, and reproduction in any medium, provided the original work is properly cited.

\begin{abstract}
Background: Based on the global predictions majority of deaths will be collectively caused by cancer, cardiovascular diseases, and traffic accidents over the coming 25 years. In planning future national health policy actions, inter - regional assessments play an important role. The purpose of the study was to analyze similarities and differences in premature mortality between Serbia, EURO A, EURO B, and EURO C regions in 2000.

Methods: Mortality and premature mortality patterns were analysed according to cause of death, by gender and seven age intervals. The study results are presented in relative (\%) and absolute terms (agespecific and age-standardized death rates per 100,000 population, and age-standardized rates of years of life lost - YLL per I,000). Direct standardization of rates was undertaken using the standard population of Europe. The inter-regional comparison was based on a calculation of differences in YLL structures and with a ratio of age-standardized YLL rates per I,000. A multivariate generalized linear model was used to explore mortality of Serbia and Europe sub-regions with In age-specific death rates. The dissimilarity was achieved with a $\mathrm{p} \leq 0.05$.

Results: According to the mortality pattern, Serbia was similar to EURO B, but with a lower average YLL per death case. YLL patterns indicated similarities between Serbia and EURO A, while SRR YLL had similarities between Serbia and EURO B. Compared to all Europe sub-regions, Serbia had a major excess of premature mortality in neoplasms and diabetes mellitus. Serbia had lost more years of life than EURO A due to cardiovascular, genitourinary diseases, and intentional injuries. Yet, Serbia was not as burdened with communicable diseases and injuries as were EURO B and EURO C.

Conclusion: With a premature mortality pattern, Serbia is placed in the middle position of the Europe triangle. The main excess of YLL in Serbia was due to cardiovascular, malignant diseases, and diabetes mellitus. The results may be used for assessment of unacceptable social risks resulting from health inequalities. Within intentions to reduce an unfavourable premature mortality gap, it is necessary to reconsider certain local polices and practices as well as financial and human resources incorporated in the prevention of disease and injury burden.
\end{abstract}




\section{Background}

The start of the new millennium was an appropriate time for the examination and reform of current health policies and practices for many countries worldwide. In addition to financial crises, health inequalities marked the beginning of the century. Based on the updated Global Burden of Disease (GBD) Study in 2004, predictions are that > $50 \%$ of all deaths will be caused collectively by cancer, cardiovascular diseases, and traffic accidents over the coming 25 years [1]. Other alerts involved divergent trends in global mortality and a slowing of improvements in life expectancy in Europe [1]. In addition, common drivers for changes in actual policies and practices have modified users' expectations and dissatisfaction with health system performance. Recent actions of public health policy professionals included setting the millennium development goals and intensification of activities for strengthening health system performance nationally and internationally [2-5].

Due to awareness of the changing settings and related financial flows, it is urgent to objectively assess national health patterns [6]. The GBD study has assisted in the balanced evaluation of health problems worldwide [7]. In fact, the GBD study is a source for accurate information on diseases, injuries, and risk factors for premature mortality, morbidity, and disability [7]. Moreover, such scientific methodology provides a specific look at the operation of a country's health system and its supporting mechanisms.

Serbia is a small country in southeast Europe; it belongs to the EURO B mortality stratum with respect to the low child and adult mortality rate [8]. After a long period of political, social, and economic instability that started with a violent split between six Yugoslav republics (including Serbia), the public health sector underwent reform [9]. The changes coincided with an economic transition from centrally-planned to market-driven. In accordance with the national orientation to enhance cross-border collaboration, the changes appeared useful to explore Serbia's mortality burden within the European context.

Former studies on the burden of diseases and injuries in Serbia aimed to introduce professionals with contemporary methodology, to include premature mortality measures in setting national health priorities, and to assess years of life lost (YLL) patterns within country regions [1012]. The Serbian Burden of Disease Study [13] was conducted to estimate national disability adjusted life years due to selected diseases, injuries, and risk factors. In planning future national health policy actions, inter-regional assessments play an important role $[14,15]$ and are even more instructive in circumstances of scarce financing. We aimed to explore beneficial directions for health improvement in Serbia.
The purpose of the study was to analyze the similarities and differences in premature mortality between Serbia, EURO A, EURO B, and EURO C regions in 2000.

\section{Methods}

The study populations were Serbia, EURO A, EURO B, and EURO C in 2000. The population of Serbia was 7,550,855 (49\% male and $51 \%$ female) [16]. The population was estimated with backward projection from the 2002 Census and without a migration component, but Kosovo and Metohija were excluded due to the unavailability of data. The Serbian electronic mortality database was obtained from the Republic's Statistical Office [16]. Data on the population, mortality, and YLL of EURO A, EURO B, and EURO C were obtained from the GBD 2000 estimates report $[8,17,18]$.

The completeness of the Serbian mortality database was $98 \%$ in 2000 [13]. The issuing and distribution of death certificates in the state is coordinated between the Ministry of Internal Affairs and the Ministry of Health [19-22]. All deaths occurring in the territory of the Republic of Serbia are registered with a completed death file (certificate of death and statistical paper DEM-2 form) $[19,20]$. The procedure is consistent throughout the country and comprises several levels of control and verification [21,22]. A death certificate can be obtained by an authorized physician in the health care organization, a coroner, or a forensic doctor. A death file contains information on the cause of death (coded with ICD-10), time and place of death, clinical or forensic postmortem data, and other personal data. The local registrar controls and forwards death files to the referral public health institute within five days, where another trained medical doctor or specialist controls and corrects the file with Death Certificate software within thirty days $[21,22]$. Authorized statistical bodies compile regional and state unit records and annually report to the public, but with a two-year lag. All the data files are confidential and considered officially undisclosed information.

For this study, mortality data with no personal identification were classified into a comprehensive list of three broad GBD groups, 21 categories of diseases and injuries, and 135 specific conditions, following the structure of the GBD list of conditions and codes [7]. The GBD methodology was used for handling ill-defined codes or missing age information. Therefore, $0.1 \%$ deaths with missing age were redistributed proportionally by gender and cause. A total of $8.7 \%$ deaths with ill-defined conditions (U161) were redistributed proportionally by age and gender, in the age group $<5$ years - across communicable diseases, maternal, perinatal, and nutritional conditions (U001); and in age groups $\geq 5$ years - within non-communicable diseases (U059). Then, 3.4\% of deaths assigned with code 
U077 of malignant neoplasms were proportionally redistributed by age and gender in all specified sites, and $0.7 \%$ of ill-defined injury deaths (U162) - across all unintentional injuries (U149). Also, 11\% of cardiovascular diseases coded U110 were redistributed to ischemic heart disease in accordance with the GBD regression formula [7].

In this paper, we analyzed diseases and injuries that were responsible for approximately $>99 \%$ of male and female mortality in Serbia in 2000. Disease categories that contributed $<0.5 \%$ to overall mortality in both genders were not presented in this analysis. Apart from the three broad GBD groups: communicable, maternal, perinatal, and nutritional conditions (U001), non-communicable diseases (U059), and injuries (U148), this study included 12 major disease categories: infectious and parasitic diseases (U002), respiratory infections (U038), perinatal conditions (U049), malignant neoplasms (U060), diabetes mellitus (U079), neuropsychiatric conditions (U081), cardiovascular diseases (U104), respiratory diseases (U111), digestive diseases (U115), genitourinary diseases (U120), unintentional injuries (U149), and intentional injuries (U156).

Mortality and premature mortality patterns were analyzed according to cause of death by gender and seven age intervals $(0-4,5-14,15-24,25-44,45-54,55-69$, and $\geq 70$ years). Consistent with the GBD Study methodology, YLL were calculated as the number of years lost from deaths occurring before the maximum attainable life expectancy at birth, with a 3\% time discount rate for YLL in the future and age-weighting [7]. To make possible the comparison with the burden of disease in other countries, we applied the GBD Study life expectancies at birth: 82.5 years for females (the Coale and Demeny model life table for West level 26) and 80 years for males (standard model life table, the Second edition of West level 25, available in the United Nations Population Division software package MORTPAK) $[23,24]$. The time discount rate stands for the net present value of a healthy life year gained in 10 years time and is worth $24 \%$ less than one gained now. In the absence of national age weights, we applied the GBD Study weights representing broad social preference in which a year of healthy life lived at young and older ages is weighted less than for other ages [7].

The study results are presented in relative (\%) and absolute terms (age-specific and age-standardized death rates per 100,000 population, and age-standardized YLL rates per 1,000). Direct standardization of rates was undertaken using the standard population of Europe [25]. A multivariate generalized linear model (GLM) was used to explore mortality of Serbia and European sub-regions due to broad GBD groups with In age-specific death rates. The dissimilarity was achieved with a $\mathrm{p} \leq 0.05$.

The inter-regional comparison of premature mortality patterns with respect to age, gender, and cause of death distribution was based on a calculation of differences in YLL structures (Serbian YLL structure minus European sub-regional YLL structure) and with a ratio of age-standardized YLL rates per 1,000 - SRR YLL (where Serbia YLL rates were the denominator).

The data analysis and graphic presentation were done in MS Office 2007, while GLM was performed with SPSS for Windows, version 15.0.

\section{Results \\ Mortality patterns}

In 2000 there were 104,042 deaths (52\% in males and $48 \%$ in females) in Serbia. Non-communicable diseases accounted for a large proportion of deaths in males and females in Serbia ( $92 \%$ and $94 \%$, respectively), EURO A ( $88 \%$ and $90 \%$, respectively), EURO B (82\% and $88 \%$, respectively), and EURO C (75\% and 92\%, respectively). Cardiovascular diseases and malignant neoplasms were collectively responsible for $>60 \%$ of total mortality, while other causes had minor shares (Table 1; see Additional file 1).

According to age-specific death rates, Serbia was significantly different from EURO B ( $1<0.005)$ and EURO C ( $<0.005$ ) for communicable, maternal, perinatal, and nutritional conditions (Figure 1a); it had higher age-specific death rates than EURO A ( $\mathrm{p}<0.005)$ for non-communicable diseases (Figure 1b), and was dissimilar statistically from Euro $C(p<0.002)$ with respect to injuries (Figure 1c).

For standardized death rates, Serbia was alike EURO A for communicable, maternal, perinatal, and nutritional conditions, and similar to EURO B for non-communicable diseases, but it had four times lower standardized death rate of injuries than EURO $\mathrm{C}$ (see Additional file 2). The four major cause categories were cardiovascular diseases, malignant neoplasms, respiratory, and digestive diseases. Additional causes were diabetes mellitus in Serbia, neuropsychiatric conditions in EURO A, and unintentional injuries in EURO B and EURO C. Males had higher standardized death rates than females due to all causes, with the exception of diabetes mellitus for which the rates for both sexes were similar (see Additional file 2).

In general, the standardized death rates were higher, particularly at $\geq 45$ years in all regions. However, malignant neoplasms start increasing at $\geq 30$ years of age in males and females of Serbia and EURO C, as do cardiovascular 
Table I: Total number of deaths and YLL by disease categories: Serbia and European sub-regions' in 2000

\begin{tabular}{|c|c|c|c|c|c|c|c|c|}
\hline \multirow[t]{2}{*}{ Selected disease categories (GBD Code) } & \multicolumn{2}{|c|}{ Serbia $^{2}$} & \multicolumn{2}{|c|}{ EURO $A^{3}$} & \multicolumn{2}{|c|}{ EURO B 3} & \multicolumn{2}{|c|}{ EURO C 3} \\
\hline & Deaths & YLL & Deaths & YLL & Deaths & YLL & Deaths & YLL \\
\hline All Causes (U000) & 104042 & 814023 & 3986734 & 24749640 & 1868999 & 20493250 & 3604321 & 37067216 \\
\hline $\begin{array}{l}\text { Communicable, maternal, perinatal and nutritional conditions } \\
\text { (UOOI) }\end{array}$ & 2350 & 36721 & 237564 & 1497486 & 174837 & 4571939 & 144426 & 3011811 \\
\hline Infectious and parasitic diseases (U002) & 700 & 9432 & 49196 & 483596 & 62031 & 1670130 & 79502 & 1664087 \\
\hline Respiratory infections (U038) & 1062 & 8729 & 169663 & 606236 & 67345 & 1447835 & 43875 & 688149 \\
\hline Perinatal conditions (U049) & 543 & 18000 & 11428 & 378876 & 40071 & 1329618 & 18072 & 599816 \\
\hline Non-communicable diseases (U059) & $9757 \mid$ & 710402 & 3553238 & 20339741 & 1579829 & 13352506 & 2991428 & 24309564 \\
\hline Malignant neoplasms (U060) & 19607 & 193978 & 1058472 & 7866460 & 281188 & 3032936 & 504448 & 5154102 \\
\hline Diabetes mellitus (U079) & 2731 & 20723 & 89452 & 446206 & 28734 & $26477 \mid$ & 21071 & 264771 \\
\hline Neuropsychiatric conditions (U08I) & 1362 & 16162 & 178278 & II 46462 & 24278 & 457106 & 37606 & 710146 \\
\hline Cardiovascular diseases (UI04) & 64013 & 393580 & 1673460 & 7434356 & 1051406 & 7108333 & 2130728 & 14636178 \\
\hline Respiratory diseases (UIII) & 4067 & 27913 & 213028 & 994519 & 72339 & 673706 & 122340 & 973063 \\
\hline Digestive diseases (UII5) & 3313 & 30726 & 183448 & 1346282 & 75004 & 943173 & 118772 & 1553977 \\
\hline Genitourinary diseases (UI20) & 1722 & 13732 & 60455 & 253777 & 25139 & 316520 & 26398 & 329485 \\
\hline Injuries (UI 48) & $4|2|$ & 66899 & 195931 & 2912413 & 114333 & 2568806 & 468468 & 9745841 \\
\hline Unintentional injuries (UI49) & 1964 & 34757 & |4049| & 1921897 & 79513 & 1778892 & 298377 & 6137215 \\
\hline Intentional injuries (UI56) & 2159 & 32140 & 55440 & 990516 & 34820 & 789913 & 170090 & 3608626 \\
\hline Other & 799 & $|4| 5 \mid$ & 103922 & 880457 & 27131 & 680316 & 33044 & 747601 \\
\hline
\end{tabular}

'EURO A constitute: Andorra, Austria, Belgium, Croatia, Cyprus, Czech Republic, Denmark, Finland, France, Germany, Greece, Iceland, Ireland, Israel, Italy, Luxembourg, Malta, Monaco, Netherlands, Norway, Portugal, San Marino, Slovenia, Spain, Sweden, Switzerland; EURO B: Albania, Armenia, Azerbaijan, Bosnia and Herzegovina, Bulgaria, Georgia, Kyrgyzstan, Poland, Romania, Serbia and Montenegro, Slovakia, Tajikistan, The FYR Macedonia, Turkey, Turkmenistan, Uzbekistan; EURO C: Belarus, Estonia, Hungary, Kazakhstan, Latvia, Lithuania, Republic of Moldova, Russian Federation, Ukraine [8];

2Source: Serbian Burden of Disease Study [13];

3Sources: Global Burden of Disease (GBD) 2000: version 3 estimates [17,18].

diseases in males of all populations, except EURO A, and in females of EURO C (see Additional file 2).

\section{Premature mortality patterns}

In Serbia, more than 800,000 total YLL were estimated, out of which males had lost $31 \%$ more years of life than females (Figure 2). The selected main disease categories caused almost all of the YLL in Serbia (99\%), EURO A (96\%), EURO B (97\%), and EURO C (98\%; Figure 3). Most YLL in Serbia were due to cardiovascular diseases (48\%) and malignant neoplasms (24\%) (Table 1).

The estimated average YLL per death for both males and females in Serbia (9 and 7 YLL, respectively) was lower than in EURO C (13 and 8 YLL, respectively) and EURO B (12 and 10 YLL, respectively). On average, perinatal conditions caused 33 YLL per death in both males and females in all regions, while malignant neoplasms caused 11 YLL in EURO B, 10 YLL in Serbia and EURO C, and 7 YLL in EURO A. Male vs. female average YLL due to cardiovascular diseases was 7 vs. 6 in Serbia, 6 vs. 3 in EURO A, 8 vs. 6 in EURO B, and 9 vs. 5 in EURO C.

Prior to 45 years of age, the population had already lost $19 \%$ of total YLL in Serbia, $23 \%$ in EURO A, 38\% in
EURO C, and $48 \%$ in EURO B. The main causes for this effect were injuries, neuropsychiatric conditions, infectious and parasitic diseases, respiratory infections, and perinatal conditions. Malignant neoplasms and cardiovascular diseases affected people aged 45 years and older.

In Serbia, total age-standardized YLL rate was 93 per 1,000 . Males had higher rates then females ( 115 vs. 72 ; see Additional file 3). Serbia had higher rates than EURO A, but lower than EURO C and EURO B for cardiovascular diseases, unintentional, and intentional injuries. Serbia and EURO $\mathrm{C}$ had similar rates of malignant neoplasms (Figure 4).

The analysis of premature mortality of Serbia within the European context included a calculation of differences in YLL structure (Figure 3), and ratios of age-standardized YLL rates - SRR YLL (according to data in Additional file $3)$.

Due to cardiovascular diseases, Serbian males and females had a surplus of YLL in comparison to their counterparts in EURO A (by 16\% and 22\%, respectively), EURO B (by $12 \%$ and $15 \%$, respectively), and EURO C (by $11 \%$ and $4 \%$, respectively). Malignant neoplasms caused addi- 

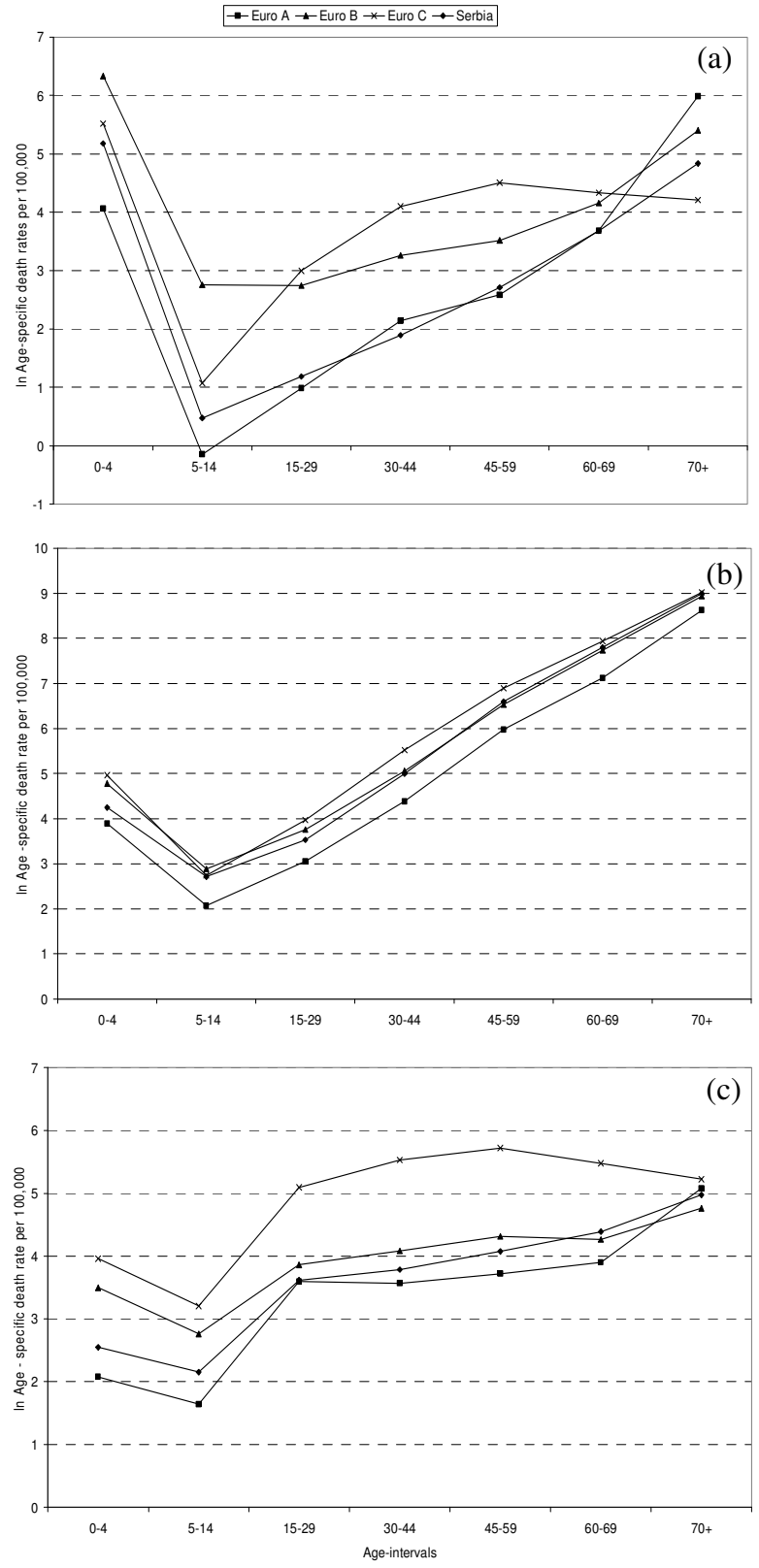

Figure I

Log-plots of age-specific death rates (per 100,000) by communicable, maternal, perinatal and nutritional conditions (a); non-communicable diseases (b); and injuries (c), in Serbia and Europe in 2000.

tional YLL excess in Serbian males and females in comparison to EURO B (by $9.4 \%$ and $8.4 \%$, respectively), and EURO C (by 12\% and 6.5\%, respectively).

With respect to SRR YLL, Serbian males and females resembled EURO B for cardiovascular and genitourinary diseases and EURO C for malignant diseases and perinatal conditions.
For SRR YLL across almost all age groups, there were higher YLL in Serbia than in EURO A in both males and females for cardiovascular diseases (0.4- and 0.3-fold, respectively), malignant neoplasms (0.8- and 0.7 -fold, respectively), diabetes mellitus ( 0.4 - and 0.3 -fold, respectively), genitourinary diseases (by 0.3 -fold in each), intentional injuries (by 0.6-fold in each), and perinatal conditions (0.3- and 0.4-fold, respectively).

With respect to SRR YLL, there were higher YLL in Serbia than in EURO B in both males and females for malignant neoplasms (by 0.8-fold in each), diabetes mellitus (by 0.7 -fold in each), and intentional injuries only among those $\geq 45$ years of age (in total, 0.9 - and 0.8 -fold, respectively).

With respect to SRR YLL, there were higher YLL in Serbia than in EURO $\mathrm{C}$ in both males and females for diabetes mellitus (0.6- and 0.4-fold, respectively), and genitourinary diseases (0.9- and 0.8-fold, respectively).

On the other hand, SRR of YLL indicated a lower burden in Serbia than in EURO B for both males and females regarding infectious and parasitic diseases (5.3- and 6.5fold, respectively), respiratory infections (5.4- and 6.0fold, respectively), perinatal conditions (1.4- and 1.6fold, respectively), unintentional injuries (1.6- and 2.0fold, respectively), and digestive diseases (1.4- and 1.7fold, respectively).

Compared to EURO C, Serbia had a lower burden of YLL in both males and females for infectious and parasitic diseases (7.1- and 2.9-fold, respectively), unintentional injuries (5.6- and 5.2-fold, respectively), intentional injuries (4.0- and 2.4-fold, respectively), respiratory infections (3.7- and 2.3-fold, respectively), digestive diseases (by 1.9-fold in each), neuropsychiatric conditions (by 1.5fold in each), and cardiovascular diseases (1.6- and 1.1fold, respectively).

\section{Discussion}

This research aimed to explore Serbian premature mortality within the European context as an extension of the national burden of disease study. Differences between Serbia and European sub-regions were identified in terms of excess YLL structures and in terms of SRR YLL for selected diseases, along with age and gender distribution. According to the mortality pattern, Serbia was similar to EURO $\mathrm{B}$, but with a lower average YLL per death case. The burden due to cardiovascular diseases and cancers accounted for approximately two-thirds of the total YLL in Serbia. YLL patterns indicated similarities between Serbia and EURO A, while SRR YLL showed similarities between Serbia and EURO B. Compared to all European sub-regions, Serbia had a major excess of premature mortality due to neo- 


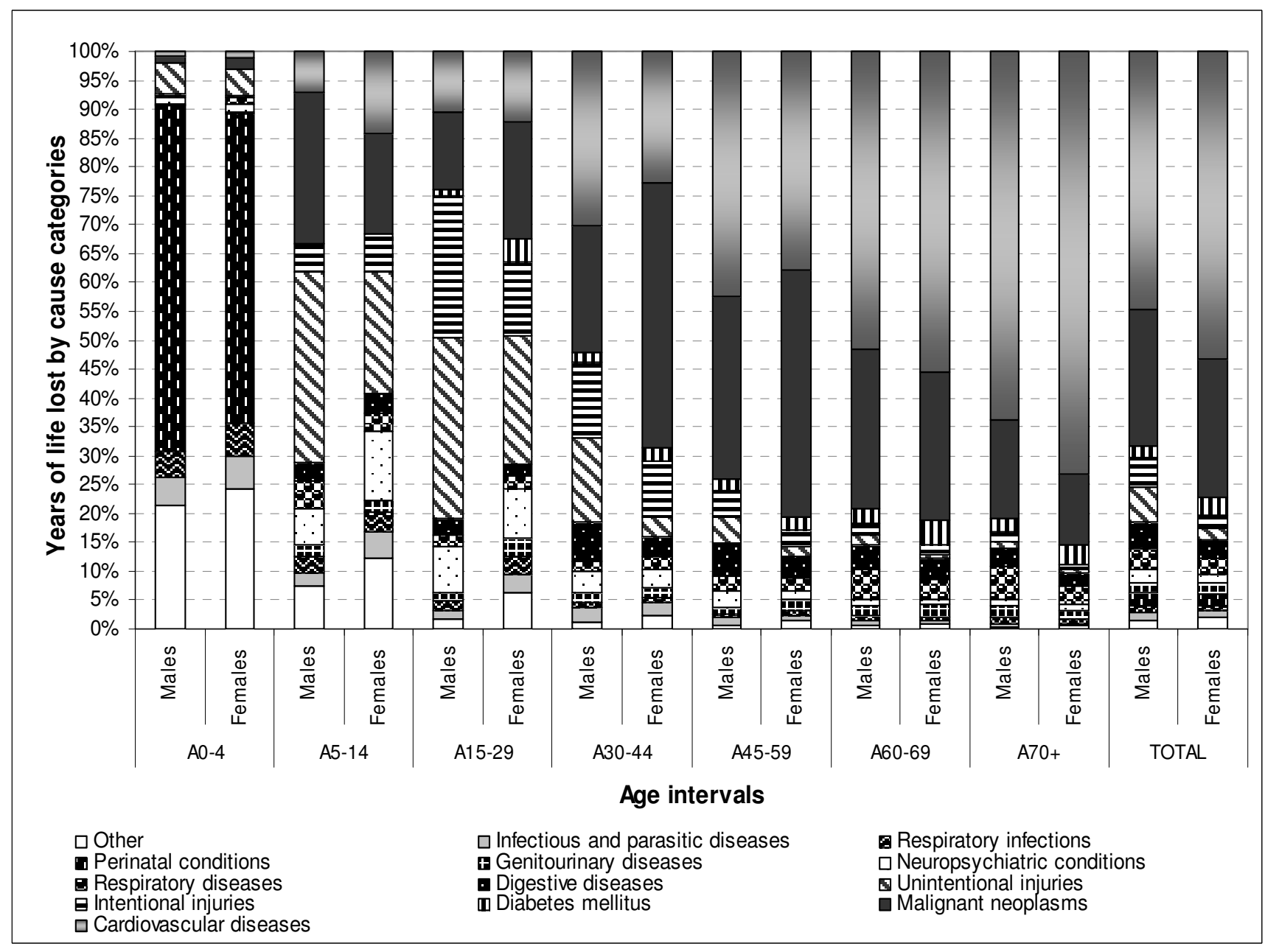

Figure 2

Distribution of selected causes of YLL (\%) by age intervals and gender in Serbia in 2000.

plasms and diabetes mellitus. Serbia had lost more years of life than EURO A due to cardiovascular, genitourinary diseases, and intentional injuries. In addition, in Serbia the major premature mortality burden shifted towards middle life years, in particular among males and due to non-communicable diseases. Yet, Serbia was not as burdened with communicable diseases and injuries as were EURO B and EURO C.

Some of the identified similarities between Serbia and Europe with respect to premature mortality were expected because of the geographical and historical conditions. Geographically, Serbia borders with countries in EURO A, the former Yugoslav republic of Croatia [8]. Also, Serbia is a neighbor of Hungary (EURO C) and the Former Yugoslav Republic of Macedonia (EURO B). Some of the disparities could be explained by social and economic circumstances $[6,26,27]$ and recent developments in Ser- bia: army conflicts accompanied with waves of internallydisplaced persons and refugees, two huge inflations in 1989 and 1993, several years of economic sanctions, and NATO bombing in 1999.

The demographic transition, biological, lifestyle, or cultural differences certainly model the mortality pattern [1]. Similar to the results of our study, males had most YLL in countries with well-established market economies (60\%), and in European countries with former socialist economies (62\%) [28]. The aging of the Serbian population (the aging index was 1 and the median age around 40 years) [16] contributed to the compression of morbidity and the predominance of non-communicable diseases among adults and the elderly. In addition, the proportion of the youngest in the Serbian population (about $16 \%$ in the age interval $0-14$ years) [16] could contribute to the allocation of burden mainly across the adult population. 


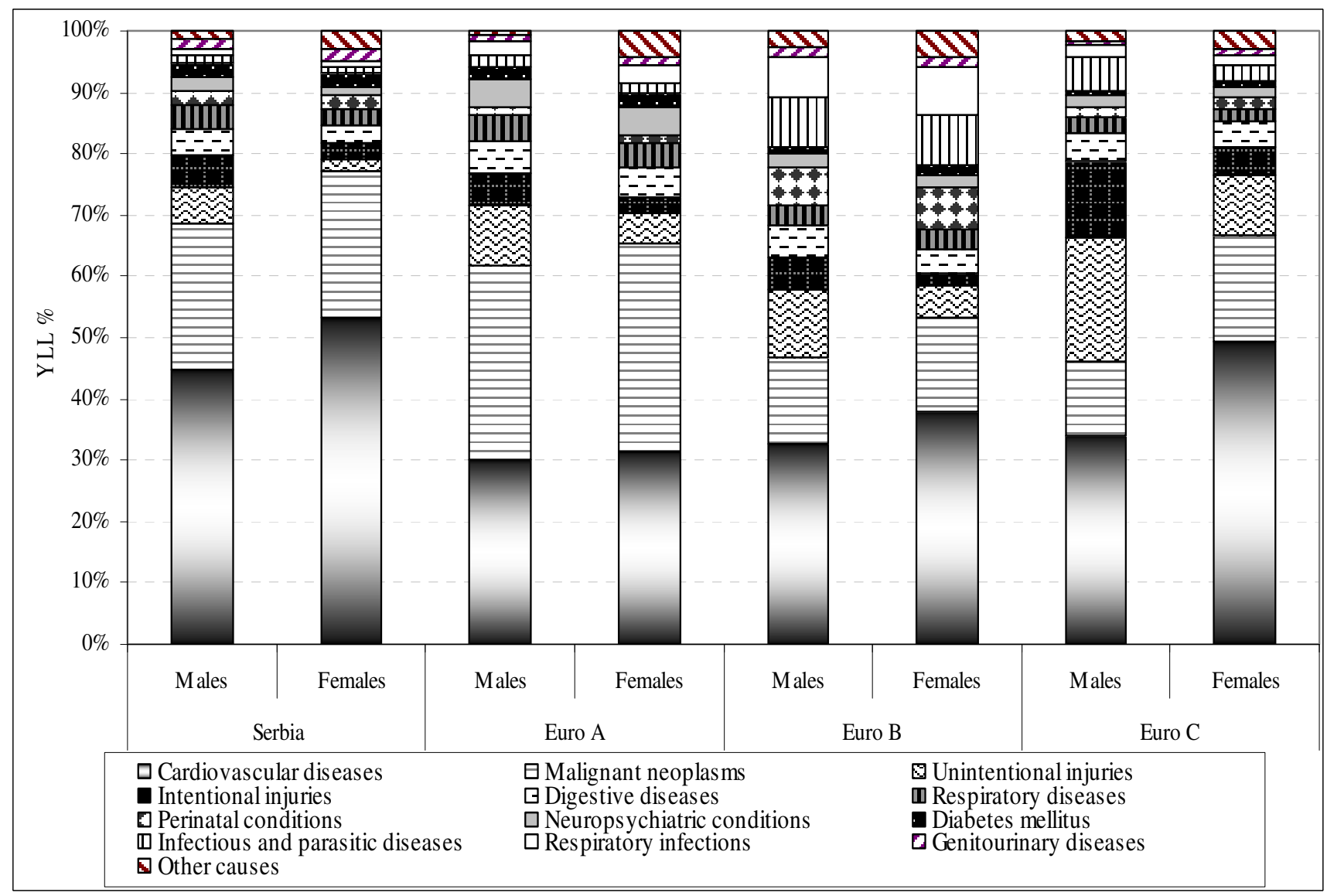

Figure 3

YLL (\%) by gender, causes, and regions in 2000.

This study had some limitations. Although Serbian registration of deaths is considered almost complete and with relatively accurate information on causes of death, $80 \%$ completeness of adult male and female mortality registration was calculated in two Serbian regions with the Brass Growth Balance method [12]. Yet, that method is more suitable for stable populations where partial birth and death rates from registered deaths have a linear relationship [29]. Nevertheless, the study findings may be biased due to various sources of mortality data, as well as different diagnostics and coding practices across compared regions. As a precaution, in a following comparative research, any improvements in the quality of data should be accounted for. For example, in Serbia data on illdefined causes of mortality were almost halved in 2006 (4.8\%) compared to 2000 (8.7\%) [30]. Advanced work of the study should consider some issues as in other studies [31-34], e.g., major conditions within cause categories, the relationship to ethnicity, residence, employment status or level of education, thus providing a more valuable tool for public health planning.
Notwithstanding the shortcomings, this is the first study that objectively quantified the premature mortality gap between Serbia and the European sub-regions. Therefore, the findings could be used to indicate convergence of current national health plans for some diseases with health plans in Europe. They advocate strategic orientation of country health planners and decision-makers for public health activities within Europe and integration of health protection in other policies at the state level. The results support country participation in intraregional collaboration that will facilitate initiatives for promotion of healthy lifestyles and better disease management and that may improve institutional health care protocols.

Mortality registration needs to be improved at all levels by modernization of control, knowledge, coding practices, and death verification procedures. This is of particular relevance regarding adult mortality under-registration, and for forensic cases, e.g. injuries, since the clinical documentation and death files are among the key elements in juridical procedures. 


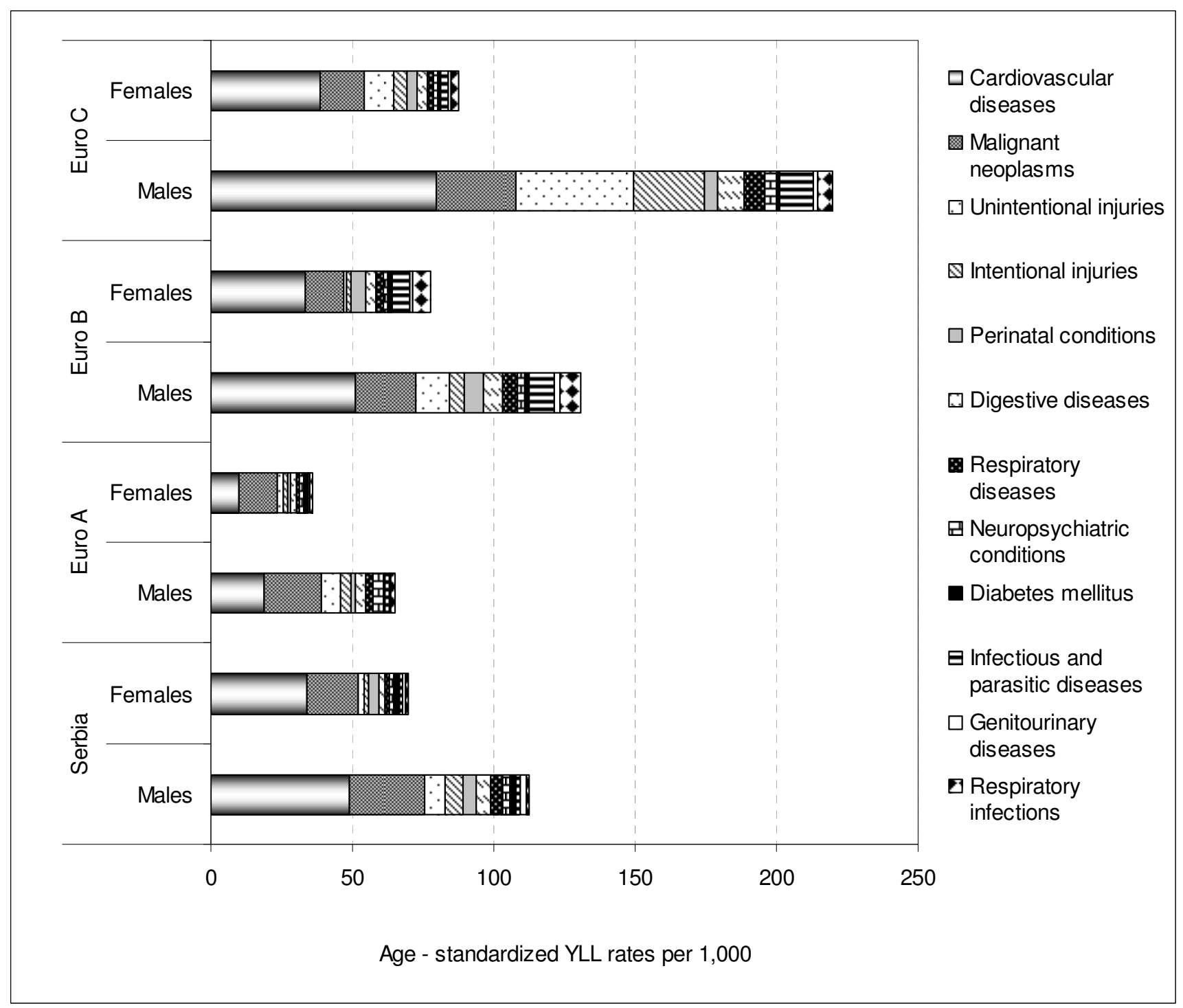

Figure 4

Age-standardized rates of YLL per I,000 by gender: Serbia and European sub-regions in 2000.

After several years of slow transition, Serbia should have a new systematic revision of the national burden of disease in order to provide a specific aspect on the health sector reform outcomes and possible improvements within the European context.

\section{Conclusion}

With a premature mortality pattern, Serbia is placed in the middle of the European triangle. The main excess of YLL in Serbia was due to cardiovascular, malignant diseases, and diabetes mellitus. These results may be used for assessment of unacceptable social risks resulting from health inequalities. In order to reduce an unfavourable premature mortality gap, it is necessary to reconsider cer- tain local polices and practices as well as the financial and human resources needed for prevention of disease and injury burden.

\section{Competing interests}

The authors declare that they have no competing interests.

\section{Authors' contributions}

MSM, VB, and ZTS made substantial contributions to the study's conception and design, analysis and interpretation of data, and drafting the manuscript. JM participated in the study's design, coordination, and critical revision for important intellectual content. NK and VV performed data acquisition and statistical analysis. DV participated 
in drafting the manuscript sequence alignment and edited the language. All authors approved the final manuscript.

\section{Additional material}

\section{Additional file 1}

Total number of deaths and YLL by disease, age, and gender in Serbia in 2000. Source: [13]. The data provided represent the distribution of the total number of deaths and years of life lost by disease, age, and gender in Serbia in 2000.

Click here for file

[http://www.biomedcentral.com/content/supplementary/14787954-7-12-S1.xls]

\section{Additional file 2}

Cause-specific age-standardized death rates per 100,000; Serbia, EURO A, EURO B, and EURO C in 2000 (standard European population). The data provided represent the distribution of cause-specific agestandardized death rates per 100,000 (standard European population), in four regions: Serbia, EURO A, EURO B, and EURO C in 2000. Click here for file

[http://www.biomedcentral.com/content/supplementary/14787954-7-12-S2.xls]

\section{Additional file 3}

Cause-specific age-standardized rates of YLL per 1,000; Serbia, EURO A, EURO B, and EURO C in 2000 (standard European population). The data provided represent the distribution of cause-specific age-standardized rates of years of life lost per 1,000 (standard European population), in four regions: Serbia, EURO A, EURO B, and EURO C in 2000. Click here for file

[http://www.biomedcentral.com/content/supplementary/14787954-7-12-S3.xls]

\section{Acknowledgements}

The authors would like to express their gratitude to the EU/European Agency for Reconstruction Project and the Ministry of Health of the Republic of Serbia for management support and funding of the Serbian Burden of Disease Study (2003). The authors thank Prof. Dr. Martin McKee for valuable suggestions on the topic.

\section{References}

I. World Health Organization: World Health Statistics Report 2008. Geneva 2008 [http://www.who.int/whosis/whostat/ EN WHS08 Full.pdf].

2. Travis P, Bennett S, Haines A, Pang T, Bhutta Z, Hyder AA, Pielemeier NR, Mills $A$, Evans $T$ : Overcoming health-systems constraints to achieve the Millennium Development Goals. Lancet 2004, 364:900-6.

3. UNDP: MDG Monitor [http://www.mdgmonitor.org].

4. WHO European Ministerial Conference on Health Systems: "Health Systems, Health and Wealth". In Tallinn, Estonia $25-27$ June 2008: report World Health Organization; 2009.

5. World Health Organization: Making Health Systems Work Series. [http://www.who.int/management/mhswork/en/index.html].

6. World Health Organization: The global burden of disease: 2004 update Geneva 2008 [http://www.who.int/healthinfo/global burden disease/ GBD report 2004update full.pdf].

7. Murray CJL, Lopez AD, eds: The global burden of disease: a comprehensive assessment of mortality and disability from diseases, injuries and risk factors in 1990 and projected to 2020. Global Burden of Disease and Injury Series Volume I. Cambridge: Harvard University Press; 1996:PP990.
8. WHO List of Member States by WHO region and mortality stratum [http://www.who.int/whr/2003/en/member states 182184 en.pdf]

9. Ministry of Health of the Republic of Serbia: Better Health in the Third Millennium. Belgrade In Serbia 2003 [http:// www.prsp.sr.gov.yu/engleski/dokumenta.jsp].

10. Pejin-Stokic L): Improvement of Planning and Financing in Health. (Introduction of the Global Burden of Disease Methodology in the Health Policy in FR Yugoslavia) Belgrade: Economics Institute \& Institute of Public Health of Serbia "Dr Milan Jovanovic-Batut"; 1996.

II. Santric Milicevic M: Setting priorities in prevention of diseases and injuries at the national level. Master of Science Thesis. University of Belgrade, School of Medicine 2002.

12. Santric Milicevic M: Years of life lost - the mortality component of the burden of disease. Specialization thesis. University of Belgrade, School of Medicine 2003.

13. Atanackovic-Markovic Z, Bjegovic V, Jankovic S, Kocev N, Laaser U, Marinkovic J, Markovic-Denic Li, Pejin-Stokic LJ, Penev G, Stanisavljevic D, Santric Milicevic M, Saulic A, Sipetic-Grujicic S, Terzic-Supic Z, Vlajinac H: The Burden of Disease and Injuries in Serbia Belgrade: Ministry of Health of the Republic of Serbia; 2003:PP330.

14. Marriotti S, D'Errigo P, Mastroeni S, Freeman K: Years of Life lost due to premature mortality in Italy. Eur J Epidemiol 2003, 18:5|3-2I.

15. Mathers CD, Loncar D: Projections of Global Mortality and Burden of Disease from 2002 to 2030. PLOS medicine 2006, 3(I l e442 [http://medicine.plosjournals.org/perlserv/?request=getdocument\&doi=10.137|/journal.pmed.0030442].

16. Statistical Office of the Republic of Serbia: Statistical Yearbook of Serbia 2002 [http://webrzs.stat.gov.rs/axd/god.htm]

17. Global Burden of Disease (GBD): version 3 estimates: Estimates of numbers of deaths by sex, cause and WHO mortality sub\begin{tabular}{l} 
region. $2000 \quad$ [http://www.who.int/healthinfol \\
\hline
\end{tabular} global burden disease/estimates regional $2000 \mathrm{v} 3 / \mathrm{en} / \mathrm{index} . \mathrm{html}]$.

18. Global Burden of Disease (GBD): version 3 estimates: Estimates of Years of Life Lost due to premature mortality by sex, cause and WHO mortality subregion. 2000 [http:// www.who.int/healthinfo/global burden disease/ estimates regional $2000 \mathrm{v} 3 / \mathrm{en} / \mathrm{index} . \mathrm{html}]$.

19. Law on main book of deaths, Official Gazette SR Serbia I5/ 90. . In Serbian

20. The By-law document of emission and form of certificate of death. Official Gazette SR Serbia 8/2005. . In Serbian

21 . The Instruction for filling and distributing the post-mortem report [http://www.izjzv.org.rs/PDF/ UPUTSTVO Izvestaj o obdukciij.pdf]. in Serbian

22. The Instruction for filling and distributing the certificate of death [http://www.izjzv.org.rs/PDF/ UPUTSTVO Potvrda \%20o smrti.pdf]

23. Coale A, Guo G: Revised regional model life tables at verylow levels of mortality. Populat Index 1989, 55:613-43.

24. Coale AJ, Demeny P, Vaughan B: Models of mortality and age composition. In Regional model life tables and stable populations 2nd edition. Edited by: Coale AJ, et al. New York: Academic Press; 1983:1-8.

25. Ahmad OB, Boschi-Pinto C, Lopez A, Murray CJL, Lozano R, Inoue M: Age Standardization of Rates: A New WHO Standard GPE Discussion Paper Series No. 31. Geneva: WHO; 2000.

26. Vogli RD, Misty R, Gnesotto R, Cornia GA: Has the relation between income inequality and life expectancy disappeared? Evidence from Italy and top industrialised countries. J Epidemiol Community Health 2005, 59:158-62.

27. Marmot M, Bobak M: International comparators and poverty and health in Europe. BMJ 2000, $321: 1$ I 24-8.

28. Vlajinac H, Marinkovic J, Kocev N, Sipetic S, Bjegovic V, Jankovic S, Stanisavljevic D, Markovic-Denic Lj, Maksimovic J: Years of life lost due to premature death in Serbia (excluding Kosovo and Metohia). Public Health 2008, 122(3):277-84.

29. Mathers CD, Vos T, Lopez AD, Salomon J, Ezzati M, eds: National Burden of Disease Studies: A Practical Guide. Edition 2.0. Global Program on Evidence for Health Policy Geneva: World Health Organization; 2001.

30. Statistical Office of the Republic of Serbia: Statistical Yearbook of Serbia 2008 [http://webrzs.stat.gov.rs/axd/god.htm]

31. Burnet NG, Jefferies SJ, Benson RJ, Hunt DP, Treasure FP: Years of life lost (YLL) from cancer is an important measure of pop- 
ulation burden - and should be considered when allocating research funds. $\mathrm{Br} J$ Cancer 2005, 92:24I-245.

32. Selb Semerl J, Sesok J: Years of Potential Life Lost and Valued Years of Potential Life Lost in Assessing Premature Mortality in Slovenia. CMJ 2002, 43(4):439-45.

33. Pham TM, Fujino Y, Ide R, Tokui N, Kubo T, Mizoue T, Ogimoto I, Matsuda S, Yoshimura T: Years of life lost due to cancer in a cohort study in Japan. Eur J Public Health 2009, 0:ckp020vl-ckp020.

34. Aragón TJ, Lichtensztajn DY, Katcher BS, Reiter R, Katz MH: Calculating expected years of life lost for assessing local ethnic disparities in causes of premature death. BMC Public Health 2008, 8: | $47 \mid-2458$.

Publish with Bio Med Central and every scientist can read your work free of charge

"BioMed Central will be the most significant development for disseminating the results of biomedical research in our lifetime. "

Sir Paul Nurse, Cancer Research UK

Your research papers will be:

- available free of charge to the entire biomedical community

- peer reviewed and published immediately upon acceptance

- cited in PubMed and archived on PubMed Central

- yours - you keep the copyright

Submit your manuscript here:

http://www.biomedcentral.com/info/publishing_adv.asp
BioMedcentral 